\title{
Tribological Properties of Sapphire under Dry Friction against Chromium and Zirconium Ceramics
}

\author{
Valery Alisin ${ }^{1, a^{*}}$ and Dmitry Gutsev ${ }^{2, b}$ \\ ${ }^{1}$ Mechanical Engineering Research Institute of the Russian Academy of Sciences, 119334, 4 \\ Bardina st, Moscow, Russia \\ ${ }^{2}$ Institut metalpolymer systems of the Belarus Academy of Sciences, 246144, 32a Kirov st., \\ Gomel, Belarus \\ avva-imash@yandex.ru, ${ }^{\mathrm{b}}$ gutsev@mpri.org.by
}

Keywords: Tribological Properties of Sapphire, Dry Friction of Crystals, Tribological Tests, Kinetic Microindentation

\begin{abstract}
The issues of sapphire friction and wear in contact with chrome steel and zirconium ceramics are discussed in this article. The kinetic microindentation method is used to study the mechanical properties of sapphire in frictional contact in modelling experiments on the indentation of a Vickers indent. Taking into account the anisotropy of the mechanical properties of sapphire, the influence of the load and orientation of the indent on the modulus of elasticity and hardness is analyzed. It has been established that, under dry friction conditions it is promising the use of zirconium ceramics in the supports of devices operating under conditions in which the use of lubricants is impossible. The possibility of using a friction couple of sapphire-zirconium ceramics in friction units operating in open space is noted.
\end{abstract}

\section{Introduction}

Sapphire refers to superhard wear-resistant materials and is widely used in friction units of precision instruments; high-strength steels serve as a counterface. Trends in the improvement of heat engines are based on an increase in the temperatures of the operating environment, therefore, there is growing interest in the use of sensors and precision mechanics instruments operating at temperatures at which it is impossible to use lubricants. The antifriction properties of aluminum oxides are not high; therefore, many works are devoted to reducing the friction coefficient and improving their tribological properties. The tribological characteristics of sapphire are strongly influenced by the surface roughness. Due to the difficulty of machining, much attention is paid to the technological issues of processing the friction surfaces of sapphire. In [1], sapphire was tested for friction with a pin-on-disk test. The disc was coated with agglomerated diamond grit. It was found that sapphire is mainly removed by an abrasive by means of plastic deformation. In work [2], the processes of grinding single-crystal sapphire with a diamond grinding wheel with a metal bond were investigated. In the process of sapphire processing, the morphology of the processed surface was observed in the sense of the workpiece surface roughness, the mechanism of the influence of the wear of the grinding wheel on the surface quality of the workpiece was investigated. It was found that when the grinding depth reaches 240 microns, the surface quality of the workpiece deteriorates. In [3], a new abrasive tool is proposed that can provide a higher finishing efficiency, as well as a better surface quality of a sapphire base in the process of chemicalmechanical grinding. The novelty of the development lies in the sintering technology of the machining tool. In work [4], the issues of ultrasonic grinding of single-crystal sapphire are considered. A new grinding method has been proposed, in which an elliptical ultrasonic vibration 
is applied to the workpiece using an ultrasonic vibrator. The grinding forces and the roughness of the working surface are measured. It has been shown experimentally that improved characteristics of diamond wheel grinding can be realized using the proposed technology. In [5], the characteristics and mechanism of scratch formation on the sapphire surface were investigated, namely, the force during scratch formation, the depth and specific energy for each direction of the scratch on the sapphire plane, taking into account the anisotropy of the mechanical properties. As a result, the direction of application of the force was established, in which the specific energy of scratching is minimal. Was investigated [6] the mechanism of changing the characteristics of wear and cutting throughout the life cycle of a diamond wire saw when cutting sapphire. A new scheme for cutting sapphire with a diamond wire saw is proposed. Work [7] is devoted to the study of dry friction of amorphous carbon nitride on sapphire and steel. A strong influence of atmospheric humidity on friction and wear has been established. Various lubricants are used to improve the tribological properties of friction couples containing sapphire. In works [8, 9], tests for friction and wear of a sapphire and stainless steel contact were carried out. For contact lubrication, a waterbased lubricant is developed by adding liquid crystals of ammonium carboxylate. Tests were carried out with linear reciprocating sliding at $75^{\circ} \mathrm{C}$ in the liquid crystal area and at $110^{\circ} \mathrm{C}$ above its melting point. Friction reduction up to $80 \%$ was found. At $110^{\circ} \mathrm{C}$, for the sapphire and AISI $316 \mathrm{~L}$ contact, there is a sharp decrease in the friction coefficient to an ultra-low steady-state value of 0.007-0.009. The influence of periodic surface structures formed by laser treatment on the coefficient of friction of silicon under dry friction was investigated [10]. Tribological tests were carried out in air using a "ball on a flat surface" nanotribometer with sapphire balls $3 \mathrm{~mm}$ in diameter as a counterface. It was found that the coefficient of friction of sapphire on a polished silicon surface remains approximately constant during the tests (in the range of 0.12-0.14) and does not depend on the applied load. There are few studies of the tribological properties of sapphire under dry friction. The aim of this work is to study the tribological properties of sapphire under dry sliding friction over a hard chromium coating of stainless steel and zirconium ceramics.

\section{Materials}

The samples were made from a single crystal of leucosapphire (synthetic sapphire), chemical formula A12O3, density $4 \mathrm{~g} / \mathrm{cm} 3$. The counterface was a chrome-plated stainless steel surface and a zirconium ceramic sintered from partially stabilized zirconia nanopowders. The chemical formula of the ceramics is $\mathrm{ZrO} 2+3 \mathrm{~mol} \% \mathrm{Y} 2 \mathrm{O} 3$.

\section{Equipment and methods}

The mechanical properties of the materials were determined by the kinetic indentation method using a MNT_Z_AE_000 microhardness tester from CSM Instruments (Switzerland) in accordance with the ISO / DIS 14577 standard with a Vickers tetrahedral indent. Friction and wear tests were carried out on the stand of reciprocating motion with the recording of the friction force by a strain gauge device. The wear of the samples was measured by the gravimetric method on a lab balance.

\section{Results}

The stability of the mechanical properties of sapphire is an important condition for ensuring the stability of the friction units of precision instruments. With regard to friction units of machines, the following are of greatest interest: modulus of elasticity (E); hardness, in this work the hardness is determined by the Vickers method by indenting a diamond pyramid with a square base (HV); characteristic of the plastic properties of surface layers (WP), determined by the size of the area bounded by the unloading curve when the indent is pressed in and by the axes of rectangular 
coordinates; force is the depth of penetration of the indent. Indentation experiments were carried out at loads from 1 to $4 \mathrm{~N}$.

Almost all crystals possess anisotropy of mechanical properties along the directions of the crystallographic axes, the determination of the directions of which is laborious and requires special equipment, which creates problems in the process of solving practical problems. In the experiments, non-oriented samples were studied, therefore, to obtain a more reliable result, the mechanical characteristics were measured at each load at three points with a rotation of 45 degrees, according to which the average values were determined. Table 1 shows the results of processing the indentation diagrams.

Table 1. Characteristics of mechanical properties of sapphire at loads from 1 to $3 \mathrm{~N}$

\begin{tabular}{|c|c|c|c|c|c|c|c|c|c|}
\hline $\mathrm{N},[\mathrm{H}]$ & \multicolumn{3}{|c|}{1} & \multicolumn{3}{c|}{2} & \multicolumn{3}{|c|}{3} \\
\hline$\alpha,[$ degree] & 0 & 45 & 90 & 0 & 45 & 90 & 0 & 45 & 90 \\
\hline $\mathrm{E}^{*},[\mathrm{GPa}]$ & 439 & 381 & 388 & 377 & 343 & 346 & 340 & 327 & 306 \\
\hline $\mathrm{HV}, \mathrm{Vickers}$ & 2702 & 2475 & 2581 & 2492 & 2320 & 2340 & 2258 & 2185 & 2122 \\
\hline $\mathrm{W},[\mu \mathrm{J}]$ & 0.58 & 0.60 & 0.59 & 1.69 & 1.73 & 1.75 & 3.24 & 3.31 & 3.46 \\
\hline $\mathrm{W}_{\mathrm{P}},[\mu \mathrm{J}]$ & 0.32 & 0.31 & 0.31 & 0.88 & 0.91 & 0.93 & 1.71 & 1.75 & 1.84 \\
\hline
\end{tabular}

There is a marked tendency towards a decrease in the values of the modulus of elasticity (Fig. 1) and hardness (Fig. 2) with an increase in the load on the indent.

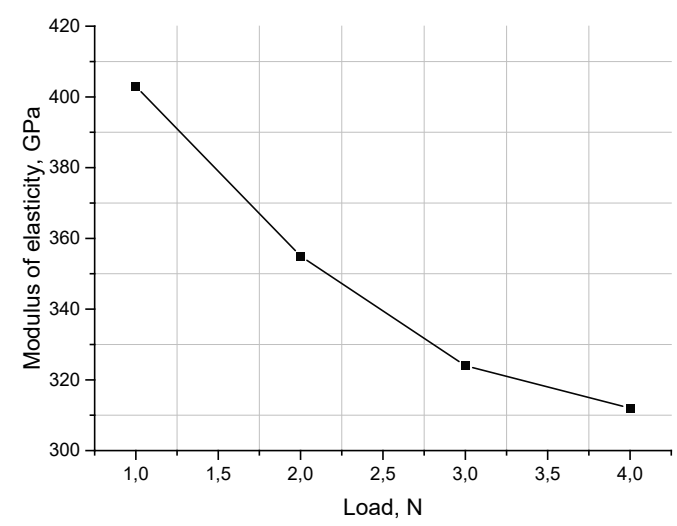

Fig. 1. Effect of load on elastic modulus

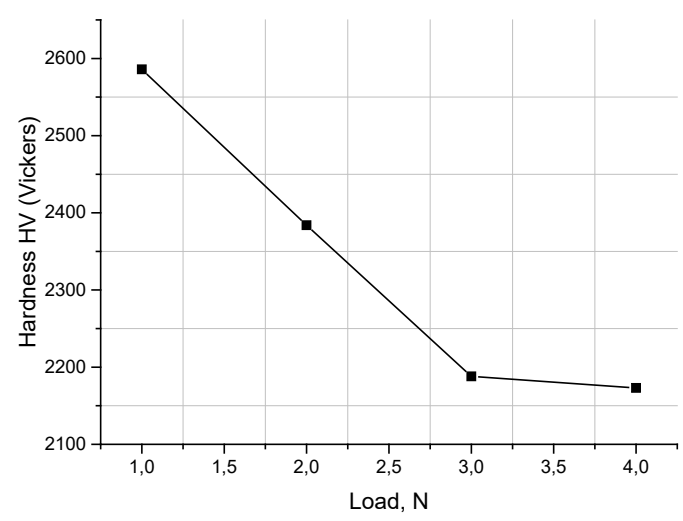

Fig. 2. Effect of load on hardness 
The coefficient of irreversible deformations equal to the ratio of irreversible energy losses $\left(\mathrm{W}_{\mathrm{P}}\right)$ to the total required work on the indentation of energy (W) changes little. The test equipment is facing increasing demands, taking into account that this study of the tribological properties of sapphire is aimed at ensuring the operability of instrumental mechanisms in the absence of lubrication. One of the main sources of measurement errors is the presence of a hinge in the holder, which serves for self-alignment of samples. To improve the fit of the samples, it is necessary that the center of rotation of the hinge is as close as possible to the plane of contact of the samples. For these tests, a holder was manufactured (Fig. 3) with a needle support for loading the sample [7].

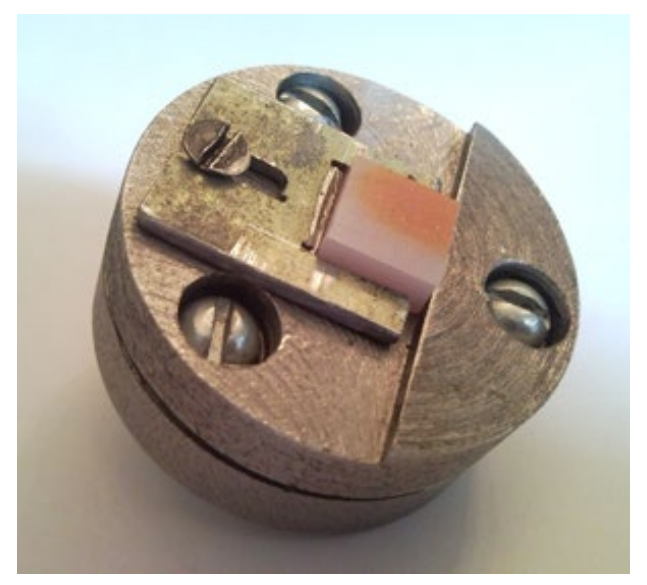

Fig. 3. General view of the holder.

The holder of the test specimen is made in the form of two interconnected disks with a clearance between their end surfaces, whereas on the inner side of one disk located on the side of the loading element, a cylindrical protrusion with a conical tip is made.

The tribological test methodology is based on measuring the wear of the samples before and after testing. Table 2 shows the results of experiments under dry friction with reciprocating motion $(\mathrm{p}=3 \mathrm{MPa}, \mathrm{V}=4 \mathrm{~mm} / \mathrm{s})$.

Table 2. Results of comparative tests of sapphire with friction against chromium and ceramics

\begin{tabular}{|c|c|c|c|c|c|c|}
\hline $\begin{array}{c}\text { Friction } \\
\text { couple }\end{array}$ & $\begin{array}{l}\text { Density } \\
{\left[\mathrm{g} / \mathrm{cm}^{3}\right]}\end{array}$ & $\begin{array}{c}\text { Path } \\
\text { friction, }[\mathrm{cm}]\end{array}$ & $\begin{array}{c}\text { Linear } \\
\text { wear, cm }\end{array}$ & $f_{0}$ & $f_{k}$ & wear rate \\
\hline $\begin{array}{l}\text { 1. Chromium } \\
\text { 2. Sapphire }\end{array}$ & $\begin{array}{c}7,2 \\
4\end{array}$ & 720 & $\begin{array}{l}0,00299 \\
0,00599\end{array}$ & 0,228 & 0,243 & $\begin{array}{l}4,2 \times 10^{-6} \\
8,3 \times 10^{-6}\end{array}$ \\
\hline $\begin{array}{l}\text { 1. Ceramics } \\
\text { 2. Sapphire }\end{array}$ & $\begin{array}{c}5,9 \\
4\end{array}$ & 720 & $\begin{array}{c}0,000031 \\
0,0000125\end{array}$ & 0,05 & 0,122 & $\begin{array}{l}4,3 \times 10^{-8} \\
1,7 \times 10^{-8}\end{array}$ \\
\hline $\begin{array}{l}\text { 1. Ceramics } \\
\text { 2. Sapphire }\end{array}$ & $\begin{array}{c}5,9 \\
4\end{array}$ & 1440 & $\begin{array}{l}0,0000339 \\
0,0000125\end{array}$ & 0,05 & 0,119 & $\begin{array}{l}2,4 \times 10^{-8} \\
9,0 \times 10^{-9}\end{array}$ \\
\hline
\end{tabular}

It was found that in the absence of lubrication, the use of chrome-plated steel axles is unacceptable, due to very high values of the coefficient of friction and very high rates of wear of surfaces. With friction against ceramics, the friction coefficient is 2 times less, and the wear resistance of the samples is more than 100 times higher. 


\section{Conclusion}

Based on the determination of the tribological properties of the friction couple sapphire and zirconium ceramics, it is advisable in the supports of devices operating under conditions of inadmissibility of the use of lubricants, for example, in controls for high-temperature heat engines, it is advisable to recommend to sapphire thrust bearings as a counterface ceramic composites based on partially stabilized zirconia. This friction couple has an acceptable coefficient of friction (not higher than 0.2) and has shown high wear resistance. Sapphire and zirconium ceramics have a very high resistance to high vacuum and high temperatures, therefore, it is of interest to use them in friction units designed for long-run operation in open space.

\section{References}

[1] Jiapeng Chen, Nannan Zhu, Fengli Niu, Yanan Peng, Jianxiu Su, Yongwei Zhu, Influence of agglomerated diamond abrasive wear on sapphire material removal behavior, Diamond and Related Materials. 108 (2020) 107965. https://doi.org/10.1016/j.diamond.2020.107965

[2] Bin Luo, Qiusheng Yan, Jisheng Pan, Jiabin Lu, Zhanliang Huang, Influences of processing parameters on metal-bonded diamond wheel wear when grinding a sapphire wafer, Diamond and Related Materials. 113 (2021) 108275. https://doi.org/10.1016/j.diamond.2021.108275

[3] Ke Wu, Daichi Touse, Libo Zhou, Wangpiao Lin, Jun Shimizu, Teppei Onuki, Julong Yuan, Chemo-mechanical grinding by applying grain boundary cohesion fixed abrasive for monocrystal sapphire, Precision Engineering. 70 (2021) 110-116. https://doi.org/10.1016/j.precisioneng.2021.01.015

[4] Zhiqiang Liang, Xibin Wang, Yongbo Wu, Lijing Xie, Zhibing Liu, Wenxiang Zhao, An investigation on wear mechanism of resin-bonded diamond wheel in Elliptical Ultrasonic Assisted Grinding (EUAG) of monocrystal sapphire, J. of Materials Processing Technology. 212/4 (2012) 868-876. https://doi.org/10.1016/j.jmatprotec.2011.11.009

[5] Wangpiao Lin, Jun Shimizu, Libo Zhou, Teppei Onuki, Hirotaka Ojima, Investigation of nanoscratch anisotropy of C-plane sapphire wafer using friction force microscope, Precision Engineering. 73 (2022) 51-62. https://doi.org/10.1016/j.precisioneng.2021.08.011

[6] Youkang Yin, Yufei Gao, Chunfeng Yang, Sawing characteristics of diamond wire cutting sapphire crystal based on tool life cycle, Ceramics International. 47/19 (2021) 26627-26634. https://doi.org/10.1016/j.ceramint.2021.06.070

[7] Xiaoxu Liu, Noritsugu Umehara, Takayuki Tokoroyama, Motoyuki Murashima, Tribological properties of ta-CNx coating sliding against steel and sapphire in unlubricated condition, Tribology International. 131 (2019) 102-111. https://doi.org/10.1016/j.triboint.2018.10.022

[8] M.D. Avilés, F.J. Carrión, J. Sanes, M.D. Bermúdez, Effects of protic ionic liquid crystal additives on the water-lubricated sliding wear and friction of sapphire against stainless steel, Wear. 408-409 (2018) 56-64. https://doi.org/10.1016/j.wear.2018.04.015

[9] M.D. Avilés, F.J. Carrión, J. Sanes, M.D. Bermúdez, Bio-based ionic liquid crystal for stainless steel-sapphire high temperature ultralow friction, Wear. 484-485 (2021) 204020. https://doi.org/10.1016/j.wear.2021.204020

[10] Alves-Lopes, A. Almeida, V. Oliveira, R. Vilar, Influence of laser surface nanotexturing on the friction behaviour of the silicon/sapphire system, Optics \& Laser Technology. 121 (2020) 105767. https://doi.org/10.1016/j.optlastec.2019.105767 